\title{
HUMANIZAÇÃO DA ENFERMAGEM
}

\author{
Marieta March * \\ Leonia Machado Borges ** \\ Maria Eliza de Souza Bonfim ***
}

\begin{abstract}
O tema em si é verdadeiramente apaixonante e, sem dúvida, ciesperta mais a atenção dos profissionais que iniciaram suas atividades há mais de duas décadas do que a daqueles que ingressaram na profissão mais recentemente. Isto é óbvio porque são aqueles profissionais que constituem a geração mais afetada pela "grande transição", cujo impacto estamos sentindo. Como diz Ferkiss(1) “... a sociedade tornou-se uma máquina. com suas peças tcdas ccncatenadas exercendo pressão sobre os indivíduos a fim de produzir resultados estandardizados, os quais vão, por sua vez, se juntar à estrutura da máquina que os originou". Forma-se, assim, um círculo vicioso: o homem passou a ser um produto do mecanismo social e uma peça deste mesmo mecanismo.
\end{abstract}

Nas sociedades atuais, em que a liberdade de ação é tão limitada, é de convir que muitos aspectos das atividades sociais merecem um estudo cuidadoso, a fim de que as soluçōes para os problemas encontrados os atinjam em suas causas reais e não em simples reflexos, o que iria, talvez, agravar ainda mais o relacionamento humano.

Nessa conjuntura enquadram-se muitos dos aspectos da atividade de enfermagem, especialmente aqueles ligados à ação da própria vontade dirigida pela sensibilidade afetiva - amor. pena, compaixão - que se vão embotando para dar lugar a uma racionalização - mais condizente com a mecanização da época atual. Não há muito tempo, um dos atributos exigidos de uma pessoa que se

* Professora de Sociologia do Departamento de Ciências Humanas do Instituto de Ciências Humanas e Filosofia da UFF.

* Professora da Escola de Enfermagem da UFF e Enfermeira da Secretaria de Saúde do Estado da Guanabara.

*** Professora da Escola de Enfermagem da UFF. 
quizesse dedicar à enfermagem era uma clara demonstração de interesse humano pelo próximo. O egoísmo, o egocentrismo não encontravam ambiente no campo da enfermagem, que então combirava o "ideal de servir" com uma técnica bastante rudimentar em relação à que hoje se desenvolve. Não sabemos se atualmente, ao ser feita a seleção vocacional, é dada a mesma ênfase a esse quesito, a par dos testes de conhecimento científico, indispensável à enfermagem moderna.

O presente trabalho não constitui numa crítica estéril, cuja tônica seja a lamentação desta "falha" que se vem manifestando no trabalho do enfermeiro; falha que, sem dúvida, abala profundamente a estrutura daquela enfermagem a que nos condicionamos e que, para nós, continua a ser a base de uma enfermagem perfeita.

Também não nos propomos a trazer soluções ao que estamos €ncarando como se fosse um problema específico da enfermagem... Nossa posição é a de que pretende colaborar no estudo de uma situação de fato, procurando apontar possíveis causas do fenômeno que tanto nos perturba. Esperamos que estudos posteriores venham a comprovar ou eliminar suas interferências, colocando o problema em suas reais proporções, condição indispensável ao seu perfeito equacionamento.

Se, na aplicação e modernização das técnicas, nós nos preocupamos com a evolução da ciência médica e a ela nos ajustamos para 0 bom desempenho de nossas funções, por que também não observarmos as profundas mudanças que se processam na sociedade a fim de sabermos que atitudes (e em que medida) devemos exigir do enfermeiro atual e em formação?

\section{MUDANÇA SOCIAL E ENFERMAGEM}

Dizem os futurólogos que a nossa era se defrorita com uma situação deveras complicada: a solução de um problema acarreta s€mpre, como decorrência da solução dada, outros (não um, mas vários) problemas que, ao serem, por sua vez, solucionados, criam. novas conjunturas problemáticas; assim em progressão geométrica, vai-se complicando a vida do homem na sociedade moderna.

Não só na enfermagem, mas em todos os setores de atividade humana, observamos o desenrolar do mesmo processo. Se pararmos um pouco e, em rápida análise retrospectiva, procurarmos ver $o$ modo por que a humanidade vem, desde os seus primórdios, promovendo recursos e desenvolvendo meios para melhorar as condições de vida física, material e espiritual, surpreendemo-nos com o descontentamento, sempre crescente, ao invés de constatarmos aque- 
la anunciada satisfação que motivou tantos movimentcs, ao seu tempo, considerados grandiosos, pelos alvos humanitários que pretendiam atingir.

A enfermagem. como importante fator da vida social, não foge, também, do esquema acima apresentado. Tendo surgido num passado remoto como expressão filantrópica, não poderia, com o evoluir da ciência médica a que presta colaboração, permanecer estática, nas bases em que a colocou o Cristianismo nascente, quando a doença ainda era tida como castigo moral e, quem dos doentes se acercasse, mereceria o opróbio da sociedade.

De filantrópica ou caritativa - assim conta a sua história a enfermagem, por volta do século XIX passou a nortear-se, não apenas pelo instinto fraternal de dar conforto e ajuda aos enfermos, mas pelos princípios da ciência curativa, abraçando normas e procedimentos úteis à restauração da saúde bem como desenvolvendo os meics eficazes para evitar a propagação das doenças. Coroando esta fase da enfermagem, surgiria a era gloriosa de Florence Nightingale, marco indelével da enfermagem técnico-científica.

De aí por diante, não mais houve lugar para improvisações nesse campo de atividade. Se alguma vez, por falta de condições econômico-sociais, ainda se improvisam enfermeiros, as justificativas apresentadas já contêm, em si mesmas, a condenação do recurso adotado. A ciência avançada trazendo o conhecimento das doenças e suas causas. A enfermidade, como castigo, não mais existia para as sociєdades civilizadas, que exigiam para os seus doentes a devida atenção, mobilizando igualmente cuidados médicos e de enfermagem. A instituição que nascera com a humanidade ganhava, assim, um novo estatuto: do sacrifício de cuidar de doentes passou à satisfação de servir cristãmente ao enfermo, dentro de técnicas que a tornaram mais eficiente; os cuidados prestados, graças ao taylorismo por ela adotado, ampliavam a ação do enfermeiro a um número maior de pacientes; e, por mais de meio século, aliou-se a técnica ao "espírito de s€rvir" ditado pelas leis cristãs.

Longe de nós banirmos completamente esse espírito humanitaristas que ainda conduz um bom número de jovens às atividades da enfermagem. Todavia, não nos devemos iludir; e seria ridículo se ignorássemos as técnicas apelativas ainda usadas para atrair os jovens a esta profissão, técnicas essas que estão perfeitamente enquadradas na conjuntura social moderna, onde o fator econômico é sempre resultado; mas, se a regra do jogo é essa, resta-nos ainda, no âmbito de formação profissional, promover o desenvolvimento de qualidades porventura latentes, despertando sentimentos capazes de atender aos reclamos que ora são feitos. 


\section{A.S IMPLICAÇÕES PSICOLÓGICAS DA VIDA SOCIAL}

Para atender a esses reclamos, cumpre-nos analisar o problema sob todos os ângulos por que se apresenta, não só para uma perfeita medida de sua extensão, como para que, ao tentar meios de solucioná-lo, tenhamos por certo que são viáveis e adequados às circunstâncias. Caso contrário, poderemos enveredar por caminhos utópicos afastando-nos da realidade em que vivemos.

1. Como primeiro ponto de abordagem caberia a pergunta: Esta necessidade é globalmente sentida, ou nós, enfermeiros mais antigos, estaremos lamentando a perda das raizes da profissão que abraçamos com amor porque era o amor ao próximo que em nossa época subsistia como legado de uma era romântica?

2. Alguns inquéritos feitos com pacientes, enfermeiros e estudantes talvez pudessem ajudar, se as técnicas utilizadas fossem de molde a determinar um pronunciamento sincero, sem interferência do controle moral que, consciente ou subconscientemente, poderia influir (no caso de enfermeiros e talvez de estudantes) mascarando a resposta.

3. O terceiro ponto da abordagem seria sabermos o lugar que numa sociedade tecnológica. como se delineia a nossa, ocupa o homem como indivíduo. Quais as suas necessidades reais? Serão as mesmas do homem de três décadas atrás? Os jovens (pacientes) com quem lidamos sentirão as mesmas necessidades de conforto, quando coentes, que sentem as pessoas de mais de 50 anos?

Será que no contexto da educação moderna (falamos dessa reeducação que fazemos a cada dia e a cada hora para nos reajustarmos à vida) ainda constataremos no indivíduo doente, um retrospecto mental na sua idade, que o faça sentir-se como criança indefesa necessitada de carinho? $E$ as crianças e os jovens cuja formação apresenta grande conteúdo de agressividade, que tipo de atenção quererão receber?

4. Descobertas e invenções têm penetrado, com seus efeitos, em todos os redutos de atividade humana, mudando sistemas, técnicas, usos e atitudes. Na medicina, novas drogas, universalmente aceitas, criam o estado de espírito em que se deseja seja mantido o paciente. Não estarão, por ventura, concorrendo para desobrigar o enfermeiro de uma das suas importantes atribuições, que era a de confortar, convencer e educar o paciente, face a determinadas circunstâncias e tratamentos?

\section{ESTRUTURA E ORGANIZAÇÃO SOCIAL}

Outro ângulo também e talvez mais importante para o nosso estudo seria o que diz respeito ao enfermeiro, no contexto social 
moderno. Não obstante o considerável aumento populacional das sociedades em expansão, cada indivíduo, na sua comunidade, desempenha um maior número de papéis do que desempenhavam os seus pais. Assim, também o enfermeiro, como qualquer outro indivíduo, se vê dentro de um complexo em que se destacam os seguintes aspectos: a) são várias as órbitas de vida social em que é obrigado a gravitar; b) não obstante, e paradoxalmente, a socialização crescente o individualismo é a tônica em nossos dias; c) o enfraquecimento religioso e a falta de uma filosofia moral que viesse a tomar o lugar da religião, tão ostensivamente abandonada, também não deveria ficar fora desta análise.

Os papéis sociais que a mesma pessoa desempenha são, muitas vezes, conflitantes, pois, enquanto mudanças em sentido progressista se efetuam numas áreas, noutras as mudanças são sentidas por defasagem. Desse modo, fica o indivíduo como ser social, à mercê de correntes opostas, sofrendo desgastantes agressōes do meio. Em tais circunstâncias, ou sucumbe ao impacto, limitando cada vez mais a sua atuação, o que pode significar alterar, para menos, a sua personalidade, ou passa a agredir para não ser agredido, reestruturando os seus papéis dentro de novos conceitos, nem sempre coincidentes com as normas de conduta anteriormente adotadas.

Não poderíamos atribuir, como desencadeadores de tais comp $s$ r tamentos, certas teorias da psicologia moderna, como por exemplo, as do ramo da psicanálise, por essas mudanças de atitude, em flagrante desacordo com a ética tradicional?

Segue-se que há nos diferentes setores da vida profissional do €nfermeiro, órgãos e autoridades cada vez mais fortes, responsáveis pela distribuição do trabalho, bem como dos recursos necessários ao seu desempenho, o que limita cada vez mais a iniciativa do indivíduo que se habitua apenas a cumprir tarefas.

As rotinas que deveriam propiciar um maior rendimento no desempenho das atividades profissionais passam a constituir desestímulo à iniciativa indiviciual, pela falta de criatividade, daí se desencadeando um processo de auto-valorização compensadora que, não raro, se caracteriza pelo desprezo à incumbência delegada.

\section{AS MODERNAS TÉCNICAS E O INSTRUMENTAL}

Outro ponto a ser considerado é a mecanização sempre crescente, que afasta o operador - no caso o enfermeiro - do paciente a seu cuidado. A impersonalidade invade o grande hospital. As técnicas vão deixando de ser manuais para entrarem na faixa da automatizaçāo. Quanto ao novo instrumental utilizado, se libera energia 
física e tempo que poderiam ser canalizados para o paciente, são, na realidade, desviados para o cuidado que pela sua complexidade ? alto custo esse mesmo instrumental requer.

\section{AS METAS DO HOSPITAL MODERNO}

O moderno planejamento hospitalar preocupa-se com os aspectos da planta física de modo a tornar suas dependências mais funcionais com a compactação das unidades de trabalho e o consequente; encurtando das distâncias nas áreas de circulação, com o material empregado na construção, visando facilitar a conservação e a limpeza; mesmo a decoração ambiente, as cores adequadas e o arrejamento conveniente são pontos favoráveis a um melhor desempenho do trabalho do enfermeiro que, com menos desgaste de energia, poderia dar outras formas de assistência ao paciente, quiçá as que se relacionam com aqueles aspectos de humanização.

A par desses aspectos há, ainda, a considerar o empenho que a moderna organização hospitalar põe na seleção do seu pessoal para, através dele, reduzir o custo operacional, de modo a ampliar o atendimento.

Quer nos parecer que também este ângulo deve ser estudado, pois, entendemos que a "ampliação" de atendimento pudesse ser obtida não só em número mas em qualidade de serviços prestados, $\mathrm{em}$ que se procurasse ver, como fator relevante, um melhor relacionamento entre enfermeiro e paciente. Isto concorreria para a recuperação deste e conseqüente redução da ocupação do leito hospitalar. Assim, sem prejuízo do aspecto econômico, estaríamos humanizando, rão só a enfermagem mas o próprio hospital.

\section{CONCLUSÃO}

Todos esses aspectos merecem, a nosso ver, um cuidadoso estudo antes que se afirme o diagnóstico e se empreenda o tratamento.

Assim, é preciso pesquisar:

1. ${ }^{\circ}$ - as causas da provável crise no relacionamento enfermeiro-paciente;

$2 .^{\circ}$ - se algum substitutivo vem se apresentando para aquele relacionamento anterior;

$3^{\circ}$ - que. procedimentos deverão ser adotados para restabelecêlc caso se constate a sua real necessidade. 


\section{BIBLIOGRAFIA}

1. FARIA. Hermínio Augusto - Três pẹsquisas, Fundação Getulio Vargas. Rio de Janeiro, 1967.

2. FERKISS, Victor C. - O homem tecnológico - mito e realidade, $1 .^{\mathrm{a}}$ ed. trad. Zahar. Rio de Janeiro, 1972.

3. FERNANDES. Cleia Alves de Figueiredo - Aspectos psicológicos da enfermagem, Rev. Bras. Enf.. Rio de Janeiro, 20 (2 e 3): $134-140$, abr/jun 1967.

4. GOOD, William e HATT. Paul K. - Métodos em pesquisa social, 4. ${ }^{\mathrm{a}}$ ed. trad. Nacional, São Paulo. 1972.

5. GOUliane, C. I. - A problemática do homem - ensaio de uma antropologia filosófica, 1. ${ }^{\mathrm{a}}$ ed. trad. Paz e Terra, - Rio de Janeiro. 1969.

6. HORTA, Wanda de Aguiar e outras - O ensaio dos instrumentos básicos de enfermagem. Rev. Bras. Enf., Rio de Janeiro, 24 (3 e 4): $159-169$, abr/jun 1971 .

7. McClAIN, Esther - C. GRACE, Shirley Hawke - Princípios científicos da enfermagem, 2. ${ }^{a}$ ed. trad. Editora Científica. Rio de Janeiro, 1970.

8. MCLUHAN, Marshall - Os meios de comunicação como extensão do homem, 3. ${ }^{\mathrm{a}}$ ed. trad. Cultrix, São Paulo. 1972.

9. ROBINSON, Joan - Liberdade e Necessidade, $1 .^{\mathrm{a}}$ ed. trad. Zahar. Rio de Janeiro, 1971.

10. SANTA BRígida, Maria de - O espírito de enfermagem. Rev. Bras. Enf. Rio de Janeiro, 20 (1): $97-100$, jan/fev 1967.

11. SANTOS, Celia A. Ferreira - Ciências Sociais em escolas de enfermagem. Rev. Bras. Enf., Rio de Janeiro, 19 (4) : 287-294, ag. 1966.

12. SOUZA, Elvira de Felice - Novo manual de enfermagem, 5. ${ }^{\mathrm{a}}$ ed. Bruno Buccini, Rio de Janeiro, 1972.

* Diretora do Serviço de Enfermagem no H.S.P.E. 